\title{
Cerebrospinal Fluid TDP-43 in Frontotemporal Lobar Degeneration and Amyotrophic Lateral Sclerosis Patients with and without the C9ORF72 Hexanucleotide Expansion
}

\author{
Anna Junttila $^{a}$ Mari Kuvaja $^{a}$ Päivi Hartikainen ${ }^{b}$ Maritta Siloaho ${ }^{a}$ \\ Seppo Helisalmi ${ }^{a}$ Virpi Moilanen ${ }^{c}$ Anna Kiviharjud, e Lilja Janssond, e \\ Pentti J. Tienari ${ }^{d}$ e Anne Marja Remes ${ }^{a}$ b Sanna-Kaisa Herukka ${ }^{a}$ b \\ a Department of Neurology, Institute of Clinical Medicine, University of Eastern Finland, \\ and ${ }^{\mathrm{b}}$ Department of Neurology, Kuopio University Hospital, Kuopio, 'Department of

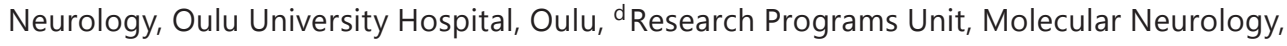 \\ Biomedicum, University of Helsinki, and e Department of Neurology, Helsinki University \\ Central Hospital, Helsinki, Finland
}

Key Words

Frontotemporal lobar degeneration · Frontotemporal dementia - Amyotrophic lateral sclerosis · TDP-43 · Cerebrospinal fluid · C9ORF72 · Biomarker · ELISA

\begin{abstract}
Background: TDP-43 is the main protein component of ubiquitinated inclusions in a subgroup of frontotemporal lobar degeneration (FTLD) and amyotrophic lateral sclerosis (ALS) patients. The C9ORF72 hexanucleotide expansion is one of the main mutations associated with TDP-43 pathology in FTLD and ALS. Our aim was to analyze cerebrospinal fluid (CSF) TDP-43 levels and Alzheimer's disease biomarkers in FTLD and ALS patients and to test whether the C9ORF72 expansion carrier status affects these variables. Methods: The patient cohort consisted of 90 clinically well-characterized FTLD $(n=69)$ and ALS $(n=21)$ patients. There were 30 patients with the C9ORF72 expansion and 60 patients without the expansion. CSF TDP-43, $A \beta_{1-42}$, t-tau, and phospho-tau levels were measured using commercial ELISA kits. Results: There was no difference in CSF TDP-43 levels between the C9ORF72 expansion carriers and the noncarriers. CSF TDP-43 levels were higher in ALS patients than in FTLD patients, and this finding was independent of the C9ORF72 expansion carrier status. Males had significantly higher TDP-43 levels than females ( $p=0.008$ in the total cohort). Conclusion: CSF
\end{abstract}

A.M.R. and S.-K.H. contributed equally to this study. 
Junttila et al.: Cerebrospinal Fluid TDP-43 in FTLD and ALS Patients with and without the C9ORF72 Hexanucleotide Expansion

TDP-43 does not seem to distinguish the C9ORF72 expansion carriers from noncarriers. However, higher CSF TDP-43 levels were detected in ALS than in FTLD, which might be an indicator of a more rapid progression of TDP-43 pathology in ALS.

(C) 2016 The Author(s)

Published by S. Karger AG, Basel

\section{Introduction}

Frontotemporal lobar degeneration (FTLD) is a genetically and neuropathologically heterogeneous group of syndromes. There are three clinically recognized subtypes: behavioral-variant frontotemporal dementia (FTD) with predominant behavioral and executive problems, and two language variants, namely progressive nonfluent aphasia and semantic dementia [1]. Amyotrophic lateral sclerosis (ALS) is a neurodegenerative disorder where the loss of motor neurons causes progressive weakness, fasciculations, and muscle atrophy. FTLD and ALS are overlapping syndromes, and about 15\% of the patients with FTLD also develop concomitant ALS (FTLD-ALS) [2]. ALS patients may also show signs of cognitive impairment, usually a type of behavioral-variant FTD [3].

The molecular pathologies of FTLD and ALS show many similar pathological features. FTLD can be divided into five subtypes of which the two main differential pathological characteristics are FTLD-TDP (TDP-43 and ubiquitin-positive, tau-negative inclusions) and FTLD-tau (tau-positive inclusions) [4]. ALS is mainly associated with TDP-43 pathology, while tau pathology is not typical in ALS. The TDP-43 protein is normally expressed in many tissues, including the brain, and it has been identified as the major component of ubiquitinpositive inclusions in the brain of FTLD patients (as shown in our own series of autopsy cases) and ALS patients [5]. It is localized in the nucleus or shifts between the nucleus and the cytoplasm [6-8]. TDP-43 proteinopathies are characterized by insoluble neuronal cytoplasmic or intranuclear inclusions and glial cytoplasmic inclusions, which aggregate in the cells [9]. Cell death results in the release of TDP-43 and, therefore, the TDP-43 levels in cerebrospinal fluid (CSF) may increase.

There have only been a few previous reports on TDP-43 levels in FTLD and ALS patients with a known genetic background. Since the C9ORF72 expansion is one of the most common genetic causes of FTLD and ALS with a TDP-43 pathology $[10,11]$ and is especially common in Finland [12], our aim was to improve the panel of possible biomarkers in the differential diagnostic process of FTLD, and we hypothesized that the C9ORF72 expansion may have an effect on CSF TDP-43 levels. Furthermore, we have previously demonstrated that changes in CSF Alzheimer's disease (AD) biomarker levels $\left(A \beta_{1-42}\right.$, t-tau, and phospho-tau) can be observed in patients carrying the C9ORF72 expansion [13]. In this study, we investigated the CSF TDP-43 as well as the CSF AD biomarker levels in clinically well-characterized FTLD and ALS patients, including both C9ORF72 expansion carriers and noncarriers.

\section{Materials and Methods}

\section{Subjects and Samples}

The patient cohort consisted of 90 clinically well-characterized FTLD ( $\mathrm{n}=69 ; 29$ males) and ALS ( $\mathrm{n}=21 ; 10$ males) patients, of whom 30 were C9ORF72 expansion carriers and 60 were noncarriers (table 1 ).

The C9ORF72 expansion ( $>45$ repeats) was detected using a repeat-primed PCR [11]. APOE genotyping was done using a PCR-based method with the forward PCR primer 5 '-GCA 
Table 1. Clinical characteristics of the patients

\begin{tabular}{|c|c|c|c|c|}
\hline & FTLD patients & ALS patients & Total patients & $\mathrm{p}$ value \\
\hline Subjects & 69 (76.7) & $21(23.3)$ & 90 & \\
\hline Age, years & $65.8 \pm 9.7$ & $61.9 \pm 8.0$ & $64.9 \pm 9.4$ & 0.961 \\
\hline Male/female & $29 / 40(42 / 58)$ & $10 / 11(47.6 / 52.4)$ & $39 / 51(43.3 / 56.7)$ & 0.008 \\
\hline MMSE & $22.1 \pm 5.2$ & $23.2 \pm 3.9$ & $22.2 \pm 5.1$ & 0.326 \\
\hline Missing cases, $\mathrm{n}$ & 7 & 15 & 22 & \\
\hline$A P O E$ allele frequency $\varepsilon 2 / 3 / 4$ & $0.06 / 0.70 / 0.24$ & $0.06 / 0.76 / 0.18$ & $0.06 / 0.72 / 0.22$ & 0.260 \\
\hline Missing cases, $\mathrm{n}$ & 20 & 4 & 24 & \\
\hline CSF TDP-43, pg/ml & $3.0 \pm 1.0$ & $4.1 \pm 1.3$ & $3.2 \pm 1.2$ & 0.001 \\
\hline $\mathrm{CSF} \mathrm{A} \beta_{1-42}, \mathrm{pg} / \mathrm{ml}$ & $647.7 \pm 244.9$ & $762.9 \pm 302.2$ & $674.6 \pm 262.2$ & 0.134 \\
\hline CSF t-tau, pg/ml & $362.7 \pm 269.7$ & $315.4 \pm 124.3$ & $351.7 \pm 243.9$ & 0.910 \\
\hline CSF phospho-tau, $\mathrm{pg} / \mathrm{ml}$ & $64.8 \pm 35.3$ & $48.4 \pm 14.2$ & $61.0 \pm 32.3$ & 0.147 \\
\hline
\end{tabular}

Values are presented as $\mathrm{n}(\%)$ or means \pm SD unless otherwise specified.

CGG CTG TCC AAG GAG CTG CAG GC-3' and the reverse PCR primer 5'-GGC GCT CGC GGA TGG CGC TGA G-3' [14]. The CSF samples were obtained by lumbar puncture during the diagnostic procedure and stored in polypropylene tubes at $-70^{\circ} \mathrm{C}$ until the analysis. The study was approved by the ethics committees of the Kuopio and Oulu University Hospitals and followed the principles of the Declaration of Helsinki. All patients agreed to participate in the study, and blood and CSF samples were obtained after receiving written informed consent from patients and/or their legal representatives.

\section{Measurements}

The CSF TDP-43 levels were measured using a commercial ELISA (Cusabio, PR China) according to the manufacturer's protocol. The kit was tested first by measuring CSF samples not intended for this study, and there was a notable drift in the values measured. The beginning of the plate gave significantly higher values than the end of the plate. Therefore, the analyses were done by using half of the plate in each run, and the drift was acceptable. All samples were measured in triplicates. The CSF A $\beta_{1-42}$, t-tau, and phospho-tau levels were measured using a commercial ELISA (Innogenetics, Ghent, Belgium) according to the manufacturer's protocol. Samples were measured in duplicates, and the results were analyzed blind to diagnosis.

\section{Statistical Analyses}

Statistical analyses were performed using SPSS 21. Statistical significance was set at $\mathrm{p}<$ 0.05. The test of normality was done using the Kolmogorov-Smirnov test and the ShapiroWilk test. Statistical analyses were performed using a t test, the Mann-Whitney test, and the $\chi^{2}$ test. Correlations were analyzed using Pearson's correlation test. All results are given as means $\pm \mathrm{SD}$, unless otherwise stated.

\section{Results}

The mean CSF TDP-43 level was $3.2 \pm 1.2 \mathrm{pg} / \mathrm{ml}$ in the total cohort (table 1 ). There was no statistically significant difference in the mean CSF TDP-43 levels between the C9ORF72 expansion carriers and noncarriers in different diagnostic groups (tables 2, 3; fig. 1a, b). Female patients had lower CSF TDP-43 levels than male patients in the total cohort $(2.9 \pm 0.9$ vs. $3.6 \pm 1.4 \mathrm{pg} / \mathrm{ml}$ in females vs. males, respectively; $\mathrm{p}=0.008$ ), in the FTLD subcohort $(2.7 \pm 0.8$ vs. $3.3 \pm 1.2 \mathrm{pg} / \mathrm{ml}$ in females vs. males, respectively; $p=0.029)$, and in the ALS 
Junttila et al.: Cerebrospinal Fluid TDP-43 in FTLD and ALS Patients with and without the C9ORF72 Hexanucleotide Expansion

Table 2. Clinical characteristics of the FTLD patients

\begin{tabular}{|c|c|c|c|c|}
\hline & $\begin{array}{l}\text { FTLD patients, } \\
\text { C9ORF72 expansion } \\
\text { positive }\end{array}$ & $\begin{array}{l}\text { FTLD patients, } \\
\text { C9ORF72 expansion } \\
\text { negative }\end{array}$ & Total patients & $\mathrm{p}$ value \\
\hline Subjects & $20(29.0)$ & $49(71.0)$ & 69 & \\
\hline Age, years & $63.3 \pm 8.4$ & $61.9 \pm 8.0$ & $65.8 \pm 9.7$ & 0.915 \\
\hline Male/female & $7 / 13(35 / 65)$ & $22 / 27(44.9 / 55.1)$ & $29 / 40(42 / 58)$ & 0.029 \\
\hline MMSE & $24.9 \pm 3.2$ & $21.0 \pm 5.5$ & $22.1 \pm 5.2$ & 0.140 \\
\hline Missing cases, $\mathrm{n}$ & 3 & 4 & 7 & \\
\hline$A P O E$ allele frequency $\varepsilon 2 / 3 / 4$ & $0.05 / 0.82 / 0.13$ & $0.07 / 0.63 / 0.30$ & $0.06 / 0.70 / 0.24$ & 0.0124 \\
\hline Missing cases, $\mathrm{n}$ & 1 & 19 & 20 & \\
\hline CSF TDP-43, pg/ml & $2.9 \pm 0.7$ & $3.0 \pm 1.1$ & $3.0 \pm 1.0$ & 0.786 \\
\hline $\mathrm{CSF} A \beta_{1-42}, \mathrm{pg} / \mathrm{ml}$ & $649.8 \pm 243.2$ & $646.8 \pm 248.1$ & $647.7 \pm 244.9$ & 0.716 \\
\hline CSF t-tau, pg/ml & $262.0 \pm 105.5$ & $403.9 \pm 304.5$ & $362.7 \pm 269.7$ & 0.871 \\
\hline CSF phospho-tau, pg/ml & $47.6 \pm 14.1$ & $71.8 \pm 38.9$ & $64.8 \pm 35.3$ & 0.548 \\
\hline
\end{tabular}

Values are presented as n (\%) or means \pm SD unless otherwise specified.

Table 3. Clinical characteristics of the ALS patients

\begin{tabular}{lcccr} 
& $\begin{array}{l}\text { ALS patients, } \\
\text { C9ORF72 expansion } \\
\text { positive }\end{array}$ & $\begin{array}{l}\text { ALS patients, } \\
\text { C9ORF72 expansion } \\
\text { negative }\end{array}$ & Total patients & p value \\
& $10(47.6)$ & $11(52.4)$ & 21 & \\
\hline Subjects & $58.6 \pm 6.5$ & $64.9 \pm 8.3$ & $61.9 \pm 8.0$ & 0.117 \\
Age, years & $4 / 6(40 / 60)$ & $6 / 5(54.5 / 45.5)$ & $10 / 11(47.6 / 52.4)$ & 0.069 \\
Male/female & 29.0 & $22.0 \pm 2.9$ & $23.2 \pm 3.9$ & 0.199 \\
MMSE & 9 & 6 & 15 & 0.407 \\
$\quad$ Missing cases, $\mathrm{n}$ & $0.06 / 0.81 / 0.12$ & $0.06 / 0.72 / 0.22$ & $0.06 / 0.76 / 0.18$ & 0.116 \\
APOE allele frequency $\varepsilon 2 / 3 / 4$ & 2 & 2 & 4 & 0.425 \\
$\quad$ Missing cases, $\mathrm{n}$ & $4.6 \pm 1.5$ & $3.7 \pm 1.0$ & $4.1 \pm 1.3$ & 0.215 \\
CSF TDP-43, pg/ml & $794.1 \pm 283.6$ & $734.6 \pm 329.2$ & $762.9 \pm 302.2$ & 0.642 \\
CSF A $\beta_{1-42, \mathrm{pg} / \mathrm{ml}}$ & $260.1 \pm 147.6$ & $365.7 \pm 73.9$ & $315.4 \pm 124.3$ & \\
CSF t-tau, $\mathrm{pg} / \mathrm{ml}$ & $39.3 \pm 7.8$ & $56.6 \pm 13.9$ & $48.4 \pm 14.2$ & \\
CSF phospho-tau, pg/ml & & & & \\
\hline
\end{tabular}

Values are presented as n (\%) or means \pm SD unless otherwise specified.

subcohort ( $3.6 \pm 0.9$ vs. $4.7 \pm 1.6 \mathrm{pg} / \mathrm{ml}$ in females vs. males, respectively; $\mathrm{p}=0.069$ ). There was no correlation between the CSF TDP-43 levels and the Mini-Mental State Examination (MMSE), age, or $A P O E \varepsilon 4$ carrier or noncarrier status in the total cohort or in different clinical phenotypes.

Interestingly, we found that the CSF TDP-43 levels were significantly higher in ALS patients than in FTLD patients in the total cohort $(p=0.001$; tables $1-3)$. A similar significant difference between the two diagnostic groups in the mean CSF TDP-43 levels was also found in patients with the C9ORF72 expansion ( $\mathrm{p}=0.003)$.

In the total cohort, there were abnormal CSF A $\beta_{1-42}$ levels in $20 \%$, abnormal CSF t-tau levels in 22\%, and abnormal CSF phospho-tau levels in $24 \%$ of patients. The portions of abnormal biomarker levels in the subgroups are shown in table 4 . All $3 \mathrm{AD}$ biomarkers were abnormal in only 3 C9ORF72 expansion noncarrier FTLD patients (4\%). Furthermore, 16 FTLD patients (23\%) had 1 abnormal biomarker, and 12 patients (17\%) had 2 abnormal biomarkers. In the ALS group, 5 patients (24\%) had 1 abnormal biomarker, and 3 patients 


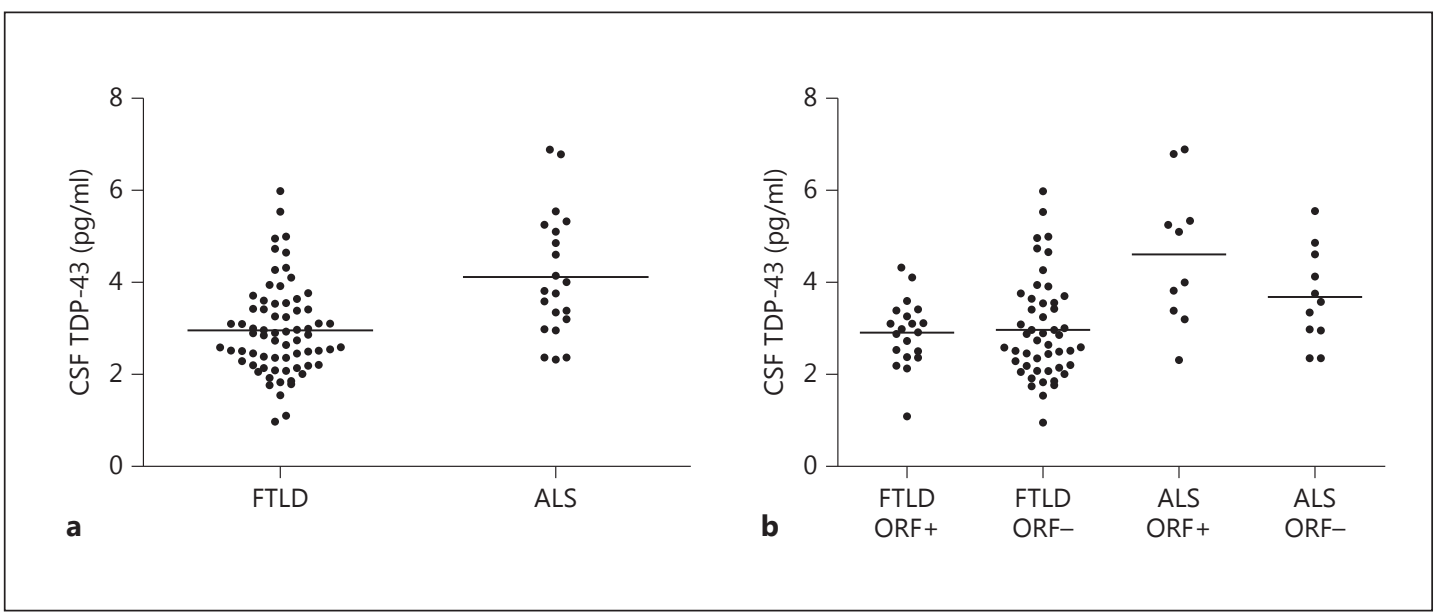

Fig. 1. a CSF TDP-43 levels in FTLD and ALS patients. b Different diagnostic groups and C9ORF72 (ORF) expansion status. The mean levels are marked by lines.

Table 4. Abnormal CSF AD biomarker level portions in the total cohort and in the subcohorts

\begin{tabular}{lllllllr}
\hline & $\begin{array}{l}\text { Total } \\
\text { cohort }\end{array}$ & $\begin{array}{l}\text { FTLD } \\
\text { patients } \\
(\mathrm{n}=69)\end{array}$ & $\begin{array}{l}\text { FTLD } \\
\text { C90RF72 } \\
\text { carriers } \\
(\mathrm{n}=20)\end{array}$ & $\begin{array}{l}\text { FTLD } \\
\text { C90RF72 } \\
\text { noncarriers } \\
(\mathrm{n}=49)\end{array}$ & $\begin{array}{l}\text { ALS } \\
\text { patients } \\
(\mathrm{n}=21)\end{array}$ & $\begin{array}{l}\text { ALS } \\
\text { C90RF72 } \\
\text { carriers } \\
(\mathrm{n}=10)\end{array}$ & $\begin{array}{l}\text { ALS } \\
\text { C90RF72 } \\
\text { noncarriers }\end{array}$ \\
\hline CSF A $\beta_{1-42}$ & $20 \%$ & $22 \%$ & $20 \%$ & $22 \%$ & $14 \%$ & $30 \%$ & $0 \%$ \\
CSF t-tau & $22 \%$ & $22 \%$ & $5 \%$ & $29 \%$ & $24 \%$ & $10 \%$ & $36 \%$ \\
CSF phospho-tau & $24 \%$ & $28 \%$ & $25 \%$ & $29 \%$ & $14 \%$ & $0 \%$ & $27 \%$ \\
\hline
\end{tabular}

(14\%) had 2 abnormal biomarkers. There were no differences in the CSF A $\beta_{1-42}$, t-tau, and phospho-tau levels between the C9ORF72 expansion carriers and noncarriers or the diagnostic subgroups. The CSF TDP-43 levels did not correlate with the CSF A $\beta_{1-42}$, t-tau, or phospho-tau levels in the total cohort nor in any subgroup either.

\section{Discussion}

Contrary to our hypothesis, we did not find any significant differences in the CSF TDP-43 levels between the C9ORF72 expansion carriers and noncarriers. There is only one previous study concerning the CSF TDP-43 levels in genetically determined FTD patients $(n=25)$ [15]. However, there were only 2 C $90 R F 72$ expansion and 3 progranulin mutation carriers in that cohort; the 3 mutation carriers had higher CSF TDP-43 levels than the remaining FTD patients without known mutations. Our analysis in a larger sample (30 C9ORF72 carriers vs. 60 noncarriers) does not support the previous finding. The contradictory findings may be due to a sample size that is still too small or the different methodology used to analyze the CSF TDP-43 levels.

We found that CSF TDP-43 was higher in patients with ALS than in patients with FTLD in the total cohort, and this phenotype-dependent correlation was also found in patients with the C9ORF72 expansion. Similar findings concerning increased CSF TDP-43 levels in patients 
with ALS compared to healthy controls have been found in a few previous studies [16-18]. One of these studies also included FTLD patients, and elevated CSF TDP-43 levels were also detected in this phenotype, while there was no difference between FTLD and ALS patients when using the immunoblot method [16]. The examined cohort was rather large $(n=39)$, but there was no information on the genetic background.

The reason for the higher CSF TDP-43 levels in ALS patients may be the faster neurodegeneration and disease progression in this patient group. The survival time after the diagnosis of ALS is usually 3-4 years, whereas FTLD patients may have a survival time of more than 10 years. The more rapid neurodegeneration in ALS may release intracellular TDP-43 from inclusions, which may lead to elevated TDP-43 levels in the CSF compared to FTLD. According to this hypothesis, CSF TDP-43 levels would be higher in patients with a more rapid progression of the disease. In the present study, survival data are not yet available, and it has to be noted that opposite results have also been presented. Noto et al. [18] found that, in patients with ALS, the highest levels of TDP-43 were detected in cases with a slower progression of the disease.

The origin of TDP-43 in the CSF has also been speculated on. In a small cohort ( $n=13)$ of FTLD and ALS patients without known genetic background, Feneberg et al. [19] studied the levels of TDP-43 in the CSF, lymphocytes, and serum by one- and two-dimensional Western blotting and quantitative mass spectrometry. They found, surprisingly, that the TDP-43 in the CSF mainly originated from blood and, thus, CSF or blood TDP-43 levels may not be a useful diagnostic tool.

We found that CSF TDP-43 levels were higher in men in the total cohort and in both the FTLD and the ALS subcohorts. In previous studies, no differences in the TDP-43 levels between men and women have been detected. The incidence and prevalence of ALS is higher in men than in women. The onset of the disease is also earlier in men, but differences in survival time have not been detected [20]. The reason for these differences is unknown, but they may be due to differences between the male and female nervous system and differences in the ability to repair damage [20]. According to this notion, it is possible that the differences in the TDP-43 levels of men and women are caused by gender-specific differences in the nervous system and in the ability to process TDP-43.

In our previous study, we investigated CSF $A D$ biomarker levels $\left(A \beta_{1-42}, t\right.$-tau, and phospho-tau) in patients with the C9ORF72 expansion, and we found decreased CSF A $\beta_{1-42}$ levels in $25 \%$ of the cases [13]. A similar profile of AD biomarkers in patients with the C9ORF72 expansion was found in the present study in both clinical phenotypes (FTLD and ALS). Changes in t-tau and phospho-tau were also detected in a significant proportion of patients with and without the C9ORF72 expansion. However, there was no difference in the CSF AD biomarker levels between C9ORF72 expansion carriers and noncarriers in the different diagnostic groups. A relatively high number of FTLD patients without the C9ORF72 expansion may represent mixed or tau-pathology, which may have been reflected in the elevation of CSF t-tau and phospho-tau levels [21,22].

There was no correlation between the APOE genotype and the CSF TDP-43 level. In the present study, the frequency of $A P O E \varepsilon 4$ was higher in $C 9 O R F 72$ expansion noncarriers than in carriers. However, the frequency of $A P O E \varepsilon 4$ in the noncarriers is the same as in the general Finnish population [23]. Interestingly, the frequency of $A P O E \varepsilon 4$ in the FTLD patients with the C9ORF72 expansion was remarkably low.

In conclusion, CSF TDP-43 levels seem to be associated with ALS and may be a marker of more rapid progression of diseases presenting with TDP-43 pathology. However, CSF TDP-43 does not seem to distinguish C9ORF72 expansion carriers from noncarriers. 
Junttila et al.: Cerebrospinal Fluid TDP-43 in FTLD and ALS Patients with and without the C9ORF72 Hexanucleotide Expansion

\section{Acknowledgements}

This study was supported by grants from Kuopio University Hospital, Emil Aaltonen Foundation, Orion Farmos Foundation, Instrumentarium Foundation, and the Finnish Cultural Foundation's North Savo Regional fund. This project was funded by the Academy of Finland (decision No. 263193) and is part of the BIOMARKAPD project in the frame of the Joint Programme for Neurodegenerative Disease (JPND). This study is part of the EU project NaDiNe.

\section{References}

1 Neary D, Snowden JS, Gustafson L, Passant U, Stuss D, Black S, Freedman M, Kertesz A, Robert PH, Albert M, Boone K, Miller BL, Cummings J, Benson DF: Frontotemporal lobar degeneration: a consensus on clinical diagnostic criteria. Neurology 1998;51:1546-1554.

-2 Burrell JR, Kiernan MC, Vucic S, Hodges JR: Motor neuron dysfunction in frontotemporal dementia. Brain 2011;134:2582-2594.

-3 Lillo P, Savage S, Mioshi E, Kiernan MC, Hodges JR: Amyotrophic lateral sclerosis and frontotemporal dementia: a behavioural and cognitive continuum. Amyotroph Lateral Scler 2012;13:102-109.

4 Mackenzie IR, Neumann M, Bigio EH, Cairns NJ, Alafuzoff I, Kovacs GG, Ghetti B, Halliday G, Holm IE, Ince PG, Kamphorst W, Revesz T, Rozemuller AJ, Kumar-Singh S, Akiyama H, Baborie A, Spina S, Dickson DW, Trojanowski JQ, Mann DM: Nomenclature and nosology for neuropathologic subtypes of frontotemporal lobar degeneration: an update. Acta Neuropathol 2010;119:1-4.

5 Pikkarainen M, Hartikainen P, Alafuzoff I: Neuropathologic features of frontotemporal lobar degeneration with ubiquitin-positive inclusions visualized with ubiquitin-binding protein p62 immunohistochemistry. J Neuropathol Exp Neurol 2008;67:280-298.

6 Arai T, Hasegawa M, Akiyama H, Ikeda K, Nonaka T, Mori H, Mann D, Tsuchiya K, Yoshida M, Hashizume Y, Oda T: TDP-43 is a component of ubiquitin-positive tau-negative inclusions in frontotemporal lobar degeneration and amyotrophic lateral sclerosis. Biochem Biophys Res Commun 2006;351:602-611.

7 Neumann M, Sampathu DM, Kwong LK, Truax AC, Micsenyl MC, Chou TT, Bruce J, Schuck T, Grossman M, Clark CM, McCluskey LF, Miller BL, Masliah E, Mackenzie IR, Feldman H, Feiden W, Kretzschmar HA, Trojanowski JQ, Lee VM: Ubiquitinated TDP-43 in frontotemporal lobar degeneration and amyotrophic lateral sclerosis. Science 2006;314:130-133.

8 Buratti E, Baralle FE: Multiple roles of TDP-43 in pre-mRNA processing and gene expression regulation. RNA Biol 2010;7:420-429.

-9 Nonaka T, Masuda-Suzukake M, Arai T, Hasegawa Y, Akatsu H, Obi T, Yoshida M, Murayama S, Mann DM, Akiyama H, Hasegawa M: Prion-like properties of pathological TDP-43 aggregates from diseased brains. Cell Rep 2013;11:124-134.

10 DeJesus-Hernandez M, Mackenzie IR, Boeve BF, Boxer AL, Baker M, Rutherford NJ, Nicholson AM, Finch NA, Flynn H, Adamson J, Kouri N, Wojtas A, Sengdy P, Hsiung GY, Karydas A, Seeley WW, Josephs KA, Coppola G, Geschwind DH, Wszolek ZK, Feldman H, Knopman DS, Petersen RC, Miller BL, Dickson DW, Boylan KB, GraffRadford NR, Rademakers R: Expanded GGGGCC hexanucleotide repeat in noncoding region of C9ORF72 causes chromosome 9p-linked FTD and ALS. Neuron 2011;72:245-256.

11 Renton AE, Majounie E, Waite A, et al; ITALSGEN Consortium, Heckerman D, Rogaeva E, Zinman L, et al: A hexanucleotide repeat expansion in C9ORF72 is the cause of chromosome 9p21-linked ALS-FTD. Neuron 2011;72:257-268.

12 Majounie E, Renton AE, Mok K, et al; Chromosome 9-ALS/FTD Consortium; French research network on FTLD/FTLD/ALS; ITALSGEN Consortium, Hernandez DG, Arepalli S, Sabatelli M, et al: Frequency of the C9orf72 hexanucleotide repeat expansion in patients with amyotrophic lateral sclerosis and frontotemporal dementia: a cross-sectional study. Lancet Neurol 2012;11:323-330.

-13 Kämäläinen A, Herukka SK, Hartikainen P, Helisalmi S, Moilanen V, Knuuttila A, Jansson L, Tienari PJ, Remes AM: CSF Alzheimer's disease biomarkers in FTLD and ALS patients with the C9ORF72 repeat expansion. Dement Geriatr Cogn Disord 2015;39:287-293.

14 Ben-Avi L, Durst R, Shpitzen S, Leitersdorf E, Meiner V: Apolipoprotein E genotyping: accurate, simple, high throughput method using ABI Prism SNaPshot Multiplex System. J Alzheimers Dis 2004;6:497-501.

-15 Suárez-Calvet M, Dols-Icardo O, Llado A, Sánchez-Valle R, Hernández I, Amer G, Antón-Aguirre S, Alcolea D, Fortea J, Ferrer I, van der Zee J, Dillen L, Van Broeckhoven C, Molinuevo JL, Blesa R, Clarimón J, Lleó A: Plasma phosphorylated TDP-43 levels are elevated in patients with frontotemporal dementia carrying a C9orf72 repeat expansion or a GRN mutation. J Neurol Neurosurg Psychiatry 2014;85:684-691.

16 Steinecker P, Hendrich C, Sperfeld AD, Jesse S, von Arnim CAF, Lehnert S, Pabst A, Uttner I, Tumani H, Lee VMY, Trojanowski JQ, Kretzschmar HA, Ludolph A, Neumann M, Otto M: TDP-43 in cerebrospinal fluid of patients with frontotemporal lobar degeneration and amyotrophic lateral sclerosis. Arch Neurol 2008;65:1481-1487. 
17 Kasai T, Tokuda T, Ishigami N, Sasayama H, Foulds P, Mitchell DJ, Mann DMA, Allsop D, Nakagawa M: Increased TDP-43 protein in cerebrospinal fluid of patients with amyotrophic lateral sclerosis. Acta Neuropathol 2009; 117:55-62.

18 Noto YI, Shibuya K, Sato Y, Kanai K, Misawa S, Sawai S, Mori M, Uchiyama T, Isose S, Nasu S, Sekiguchi Y, Fujimaki Y, Kasai T, Tokuda T, Nakagawa M, Kuwabara S: Elevated CSF TDP-43 levels in amyotrophic lateral sclerosis: specificity, sensitivity, and a possible prognostic value. Amyotroph Lateral Scler 2011;12:140-143.

19 Feneberg E, Steinacker P, Lehnert S, Schneil A, Walther P, Thal DR, Linsenmeier M, Ludolph AC, Otto M: Limited role of free TDP-43 as a diagnostic tool in neurodegenerative diseases. Amyotrophic Lateral Scler Frontotemporal Degener 2014;15:351-356.

20 McCombe PA, Henderson RD: Effects of gender in amyotrophic lateral sclerosis. Gend Med 2010;7:557-570.

21 Bieniek KF, Murray M, Rutherford N, Castanedes-Casey M, DeJesus-Hernandez M, Liesinger AM, Baker MC, Boylan KB, Rademakers R, Dickson DW: Tau pathology in frontotemporal lobar degeneration with C9ORF72 hexanucleotide repeat expansion. Acta Neuropathol 2013;125:289-302.

22 King A, Al-Sarraj S, Troakes C, Smith B, Maekawa S, Iovino M, Spillantini MG, Shaw CE: Mixed tau, TDP-43 and p62 pathology in FTLD associated with a C90RF72 repeat expansion and p.Ala239Thr MAPT (tau) variant. Acta Neuropathol 2013;125:303-310.

23 Ehnholm C, Lukka M, Kuusi T, Nikkilä E, Utermann G: Apolipoprotein E polymorphism in the Finnish population: gene frequencies and relation to lipoprotein concentrations. J Lipid Res 1986;27:227-235. 